ECCOMAS

Proceedia
COMPDYN 2021

$8^{\text {th }}$ ECCOMAS Thematic Conference on Computational Methods in Structural Dynamics and Earthquake Engineering M. Papadrakakis, M. Fragiadakis (eds.) Streamed from Athens, Greece, 28 - 30 June 202

\title{
SEISMIC PROTECTION OF CULTURAL HERITAGE ARTEFACTS BY MEANS OF ELASTOMERIC ISOLATORS: A CASE STUDY
}

\author{
Davide Pellecchia $^{1}$, Stefania Lo Feudo ${ }^{2}$, Nicolò Vaiana ${ }^{1}$, Jean-Luc Dion ${ }^{2}$, and \\ Luciano Rosati ${ }^{1}$ \\ ${ }^{1}$ Department of Structures for Engineering and Architecture, University of Naples Federico II \\ via Claudio 21, 80125 Naples, Italy \\ davide.pellecchia@unina.it \\ ${ }^{2}$ QUARTZ-SUPMÉCA - Institut Supérieur de Mécanique de Paris \\ 3 rue Fernand Hainaut, 93407 Saint-Ouen, France \\ stefania.lofeudo@supmeca.fr
}

\begin{abstract}
We investigate the rocking response of a Caryatid from the Erechtheion, modelled as a rigid body freestanding on an isolation system made of Lead Rubber Bearings. An efficient uniaxial phenomenological model belonging to a recently developed class is used to simulate the strongly nonlinear response typically exhibited by elastomeric devices. The algebraic nature of the proposed hysteretic model allows one to obtain the device restoring force by solving an algebraic equation, thus reducing the computational effort of the nonlinear dynamic analyses that have been carried out on the above-mentioned Caryatid statue. In order to establish the effective performances of the proposed isolation system the isolated and non-isolated rocking responses of the statue are derived and compared.
\end{abstract}

Keywords: Seismic Protection; Art Objects; Elastomeric Isolators; Lead Rubber Bearings; Hysteretic Model. 


\section{INTRODUCTION}

Nowadays the large majority of statues contained in museums are not equipped to resist oscillations induced by earthquakes. For this reason, seismic protection of artefacts belonging to the cultural heritage is a topic that has received significant interest over the last years $[1,2$, $3,4,5,6,7,8]$. In particular, researchers focused on the study of the rocking behaviour of rigid bodies since the statues, which are simply supported on the floor or a pedestal, could overturn under seismic excitation. Moreover, their overturning and damage is potentially associated with significant human and economic losses [9, 10].

Base isolation represents one of the most adopted strategies for the seismic protection of artefacts belonging to the cultural heritage. In fact, such a technique has been used for the protection of some statues in Italy, such as the Riace bronzes exhibited in the Archaeological Museum in Reggio Calabria [11], the Dancing Satyr at the Dancing Satyr Museusm in Mazara del Vallo, and the Imperatore Germanico at the Edilberto Rosa Museusm in Amelia [12].

The most used isolation device - mostly for the seismic protection of buildings and bridges - are the Elastomeric and Sliding isolators. The formers provide energy dissipation by using an elastomeric material, whereas the latters display an energy dissipation capacity due to the friction damping occurring at the sliding interface. Both seismic isolation bearings display a force-transverse displacement relationship of hysteretic nature.

The dynamics of a base-isolated rigid body strictly depends on the interaction between the complex nonlinear behaviour of the isolation devices and the rocking behaviour of the rigid body. Consequently, it is very important to adopt a hysteretic model able to accurately predict the seismic isolators response.

In this paper, we investigate the rocking response of a Caryatid from the Erechtheion, modelled as a rigid body freestanding on an isolation system made of Lead Rubber Bearings, i.e. one of the most popular elastomeric isolators used in Civil Engineering applications.

The behaviour of the elastomeric devices is predicted by using an efficient uniaxial phenomenological model belonging to a recently developed class [13, 14, 15]. Since the model has an algebraic nature, the device restoring force is computed by solving an algebraic equation so that the numerical solution of a first-order nonlinear ordinary differential equation at each time step of the analysis is not required. Moreover, the model is based on a small set of parameters having a clear mechanical significance.

Nonlinear dynamic analyses are carried out on the above-mentioned Caryatid statue, with and without isolation, in order to establish the performance of the latter in protecting the analysed art object from seismic excitations.

\section{SEISMICALLY ISOLATED RIGID BODY MODEL}

The Caryatid from the Erechtheion under investigation has been modelled as a symmetric rigid body freestanding on an isolation system made of elastomeric bearings. We supposed that the friction between the statue and the isolated base is high enough to avoid the sliding.

The geometrical parameters of the model are shown in Fig. 1(a), namely the distance $R$ between the centre of gravity and the centre of rotation, and the slenderness $\gamma$ measured as the tilt angle relative to the vertical axis when the body is at rest. Their values are taken from a paper by Constantinides et al. [16] who studied the seismic response of six statues belonging to a collection shown at the University of California, Berkeley.

The Caryatid's mass $m$, equal to $3172.05 \mathrm{~kg}$, has been obtained supposing that the density of Caryatid's material is equal to $2650 \mathrm{~kg} \mathrm{~m}^{-3}$. Hence, the Caryatid's fundamental angular 


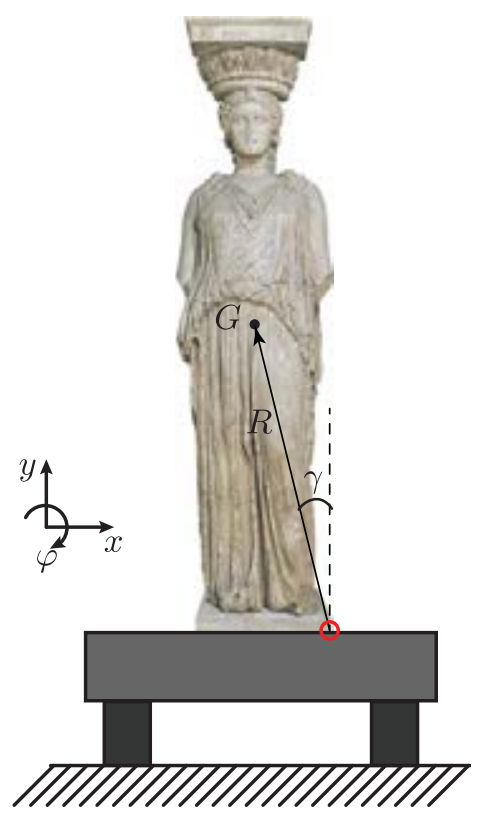

(a) Geometrical properties

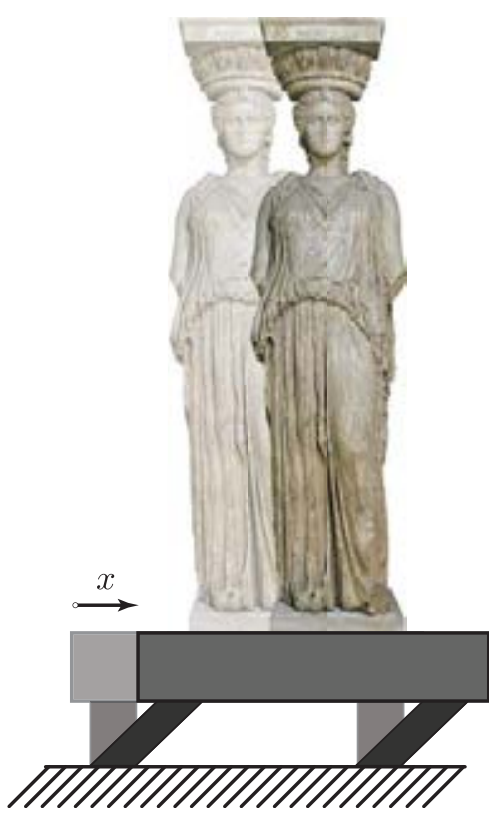

(b) Full-contact phase

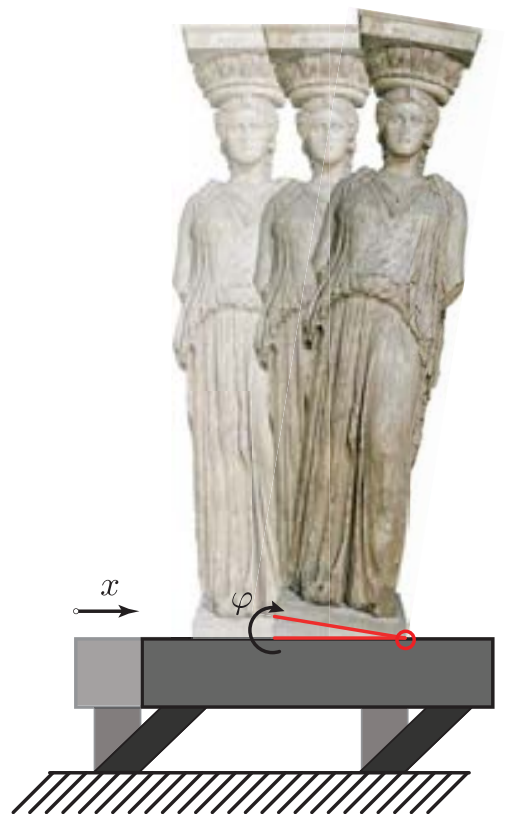

(c) Rocking phase

Figure 1: The Caryatid from the Erechtheion.

rocking frequency is given by

$$
\omega_{r}=\sqrt{\frac{m g R}{J_{O}}} \approx 2.60 \mathrm{rad} \mathrm{s}^{-1}
$$

where $g$ is the gravity acceleration and $J_{O}$ is the polar inertia around one of the two Caryatid's centre of rotation.

Finally, the mass of the isolated base $m_{b}$ is supposed to equal to $212 \mathrm{~kg}$.

\subsection{Kinematic phases}

There are two phases of motion that can occur, namely the full-contact and the rocking motion. The former is described by one degree of freedom, i.e. the horizontal movement of the base $x(t)$, whereas in the latter there are two degrees of freedom activated: one is the horizontal movement and the other measures the tilt angle of the body $\varphi(t)$.

The equations of motion change depending on the phase of motion that the rigid body undergoes.

\subsection{The full-contact motion}

In the full-contact phase, the Caryatid does not rock while the isolated base moves as shown in Fig. 1(b).

The equation of motion that describes this phase is

$$
\left(m+m_{b}\right)\left(\ddot{x}_{g}+\ddot{x}\right)+n_{d} f=0,
$$

where $\ddot{x}_{g}$ is the ground acceleration, $n_{d}$ is the number of devices that support the isolated base and the statue, and $f$ is the generalised restoring force of the elastomeric isolator. 


\subsection{The rocking motion}

Fig. 1(c) illustrates the rocking motion. In this phase, the Caryatid rocks while the isolated base moves; thus there are two degrees of freedom activated.

By using the signum function $\operatorname{sgn}(\cdot)$, as shown in [3], this phase can be described by just one set of two equations, regardless of the centre of rotation around which the Caryatid rocks. Hence, we have

$$
\begin{aligned}
& m\left(\ddot{x}_{g}+\ddot{x}+\ddot{x}_{\varphi}\right)+m_{b}\left(\ddot{x}_{g}+\ddot{x}\right)+n_{d} f=0, \\
& J_{O} \ddot{\varphi}+m\left(\ddot{x}_{g}+\ddot{x}\right) R \cos (\operatorname{sgn}(\varphi) \gamma-\varphi)=-m g R \sin (\operatorname{sgn}(\varphi) \gamma-\varphi),
\end{aligned}
$$

in which $\ddot{x}_{\varphi}$ is the acceleration of the centre of mass relative to the ground. This acceleration depends on the rocking angle $\varphi$, since

$$
x_{\varphi}=\operatorname{sgn}(\varphi) R \sin (\gamma)-R \sin (\operatorname{sgn}(\varphi) \gamma-\varphi) .
$$

Consequently, the second derivative with respect to the time of (5) is:

$$
\ddot{x}_{\varphi}=R \sin (\operatorname{sgn}(\varphi) \gamma-\varphi) \dot{\varphi}^{2}+R \cos (\operatorname{sgn}(\varphi) \gamma-\varphi) \ddot{\varphi} .
$$

\subsection{Collisions}

As usual in the specialised literature, we assume that when the Caryatid collides with the isolated base, the linear (angular) momentum remains unchanged whereas the linear (angular) kinetic energy decreases. Accordingly, the angular and the linear coefficients of restitution obtained by the law of momentum conservation are [2]:

$$
e_{\varphi}=1+\frac{2 R^{2} \sin ^{2}(\gamma) m}{R^{2} \cos ^{2}(\gamma) m \tilde{m}-J_{O}}
$$

and

$$
e_{x}=\frac{2 R^{4} \sin ^{2}(\gamma) \cos ^{2}(\gamma) m \tilde{m}}{R^{2} \cos ^{2}(\gamma) m \tilde{m}-J_{O}}
$$

where $\tilde{m}=m /\left(m+m_{b}\right)$.

\section{LEAD RUBBER BEARINGS AND THEIR MATHEMATICAL MODEL}

Elastomeric isolators are one of the most popular devices used for the protection of mechanical and civil systems from seismic events. They are characterised by layers of elastomeric materials and thin reinforcing elements. Elastomers provide energy dissipation and flexibility, whereas the reinforcing elements avoid the lateral expansion of the elastomer due to the axial compressive load.

In this Section, the main characteristics of Lead Rubber Bearings (LRBs) - one of the most used types of elastomeric isolators - are illustrated. In addition, the proposed hysteretic model, able to predict the complex hysteretic behaviour of such isolators, is described.

\subsection{Lead Rubber Bearings}

Lead Rubber Bearings have a circular or square transverse cross-section and are connected with the superstructure and the substructure by means of two steel plates bounded to the top and the bottom surfaces of the devices, see Fig. 2(a). Additionally, they are characterised by one or more lead cores that provide high values of horizontal stiffness and energy dissipation. In particular, the damping factor of such devices can reach a value up to $\xi \approx 15 \div 35 \%$. Fig. 2(b) shows the typical hysteresis loop shape displayed by LRBs. 


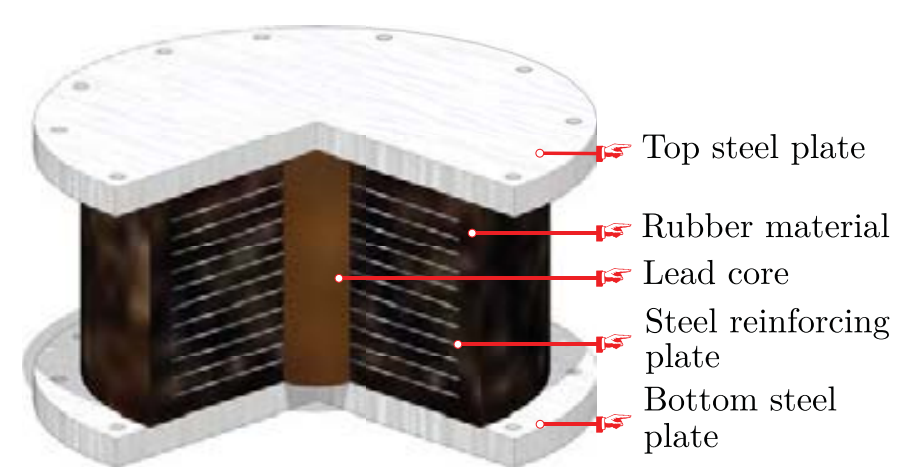

(a) Cutaway drawing

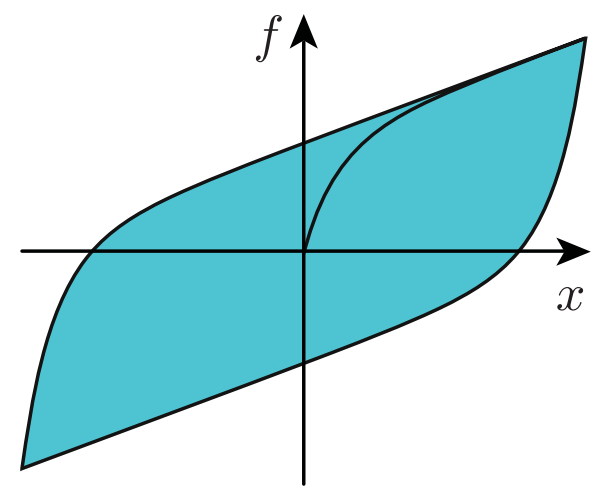

(b) Restoring force-displacement hysteresis loop

Figure 2: Lead Rubber Bearing.

\subsection{Proposed hysteretic model}

In this Section, we present the proposed hysteretic model able to predict the complex behaviour of the LRBs isolators. The accuracy and the computational efficiency of such a model have been demonstrated in previous papers $[13,17]$, by comparison with the celebrated BoucWen model $[18,19]$. In fact, the latter model requires the numerical solution of a differential equation to compute the restoring force of the device, what increases the overall computational effort. On the contrary, the proposed hysteretic model is of algebraic nature, i.e. the restoring force can be computed by means of algebraic equations; moreover, the model is based on just three constitutive parameters that can be calibrated from experimental tests [20] or by means of a design procedure described in [21].

Making reference to [22] for further details, the generic hysteresis loop is modelled by four types of curves, namely the upper (lower) limiting curve $c_{u}\left(c_{l}\right)$ and the generic loading (unloading) curve $c^{+}\left(c^{-}\right)$, as shown in Fig. 3. The point of intersection between the upper (lower) limiting curve and the axis of ordinate is denoted as $f_{0}\left(-f_{0}\right)$. In addition, the starting and the ending points of the generic loading (unloading) limiting curve have abscissa $x_{i}^{+}$and $x_{j}^{+}\left(x_{i}^{-}\right.$ and $x_{j}^{-}$), respectively. The model assumes that the horizontal distance between the starting and the ending points for both loading and unloading curves is constant and equal to $2 x_{0}$, where $x_{0}$ is an internal model parameter.

The restoring force in the generic loading case is equal to $f=c^{+}$when $x_{i}^{+}<x<x_{j}^{+}$and $f=c_{u}$ when $x>x_{j}^{+}$; whereas $f=c^{-}$when $x_{j}^{-}<x<x_{i}^{-}$and $f=c_{l}$ when $x<x_{j}^{-}$.

The expressions of the upper (lower) and the loading (unloading) limiting curves used for predicting the hysteretic behaviour of LRBs are

$$
\begin{aligned}
c_{u} & =k_{b} x+f_{0}, \\
c_{l} & =k_{b} x-f_{0},
\end{aligned}
$$

and

$$
\begin{aligned}
& c^{+}=k_{b} x+\left(k_{a}-k_{b}\right)\left[\frac{\left(1+x-x_{j}^{+}+2 x_{0}\right)^{(1-\alpha)}}{1-\alpha}-\frac{\left(1+2 x_{0}\right)^{(1-\alpha)}}{1-\alpha}\right]+f_{0}, \\
& c^{-}=k_{b} x+\left(k_{a}-k_{b}\right)\left[\frac{\left(1+x-x_{j}^{-}+2 x_{0}\right)^{(1-\alpha)}}{\alpha-1}-\frac{\left(1+2 x_{0}\right)^{(1-\alpha)}}{\alpha-1}\right]-f_{0},
\end{aligned}
$$




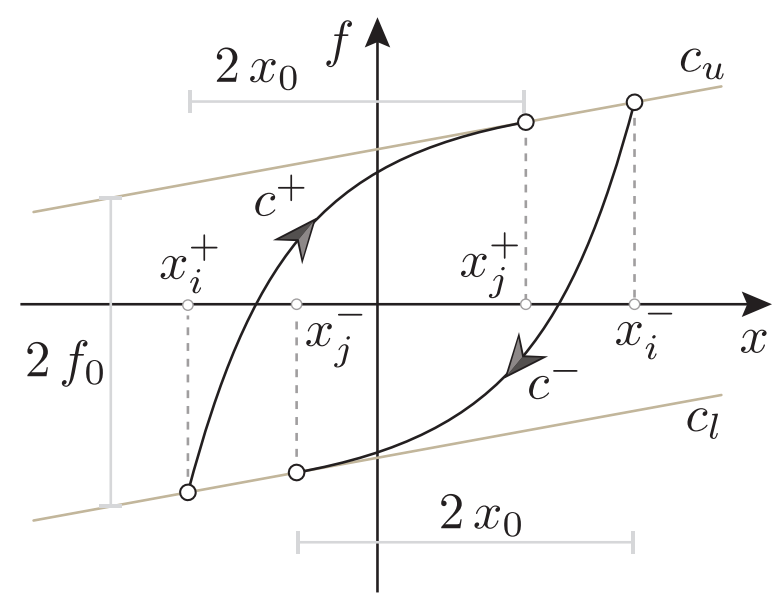

Figure 3: Proposed hysteretic model.

where $k_{a}, k_{b}$ and $\alpha$ are the model's constitutive parameters. The mechanical significance of these parameters is illustrated in [22].

Finally, the internal model parameters $x_{0}$ and $f_{0}$ are computed as follows:

$$
\begin{aligned}
& x_{0}=\frac{1}{2}\left[\left(\frac{k_{a}-k_{b}}{\delta_{k}}\right)^{\frac{1}{\alpha}}-1\right] \\
& f_{0}=\frac{k_{a}-k_{b}}{2}\left[\frac{\left(1+2 x_{0}\right)^{(1-\alpha)}-1}{1-\alpha}\right],
\end{aligned}
$$

in which $\delta_{k}$ may be set equal to $10^{-20}$, as shown in [13].

\section{APPLICATION TO A CARYATID FROM THE ERECHTHEION}

In this Section, we show the results obtained from some nonlinear time history analyses on the Caryatid from the Erechtheion described in Sec. 2. The East-West component of ground acceleration recorded at the AI_011_DZC station during the Düzce earthquake (Turkey), that occurred on the $12^{\text {th }}$ of November 1999, is used as seismic input. Such an acceleration, displayed in Fig. 4(a), has been taken from the Engineering Strong Motion (ESM) database [23]. The rocking response of the non-isolated Caryatid subjected to the above-mentioned acceleration is shown in Fig. 4(b). As a result, the Caryatid needs to be protected since, due to the assumed excitation, it overturns after approximately thirty-five seconds.

Firstly, we built the Caryatid's rocking spectrum when it is subjected to the Düzce earthquake acceleration, see Fig. 5(a), where $T_{r}$ refers to the rocking period. We observe that the Caryatid is vulnerable to such an excitation when its rocking period is less than four seconds. Hence, the base isolation will be efficient if it increases the Caryatid rocking period above four seconds.

Fig. 5(b) shows the horizontal displacement spectrum referred to the isolated Caryatid with LRBs devices by increasing the viscous damping factor, where $T_{b i}$ is the isolation period. This spectrum allows one to infer the isolation period and the equivalent viscous damping factor providing a displacement less than the device's maximum allowed displacement, $x_{\max }$.

Fig. 6 illustrates the time histories of the rocking angle (a) and displacement (b) of the baseisolated Caryatid characterised by the properties shown in Tab. 1(a). The adopted constitutive parameters of the model are shown in Tab. 1(b). Such parameters have been obtained from the design procedure described in [21]. 


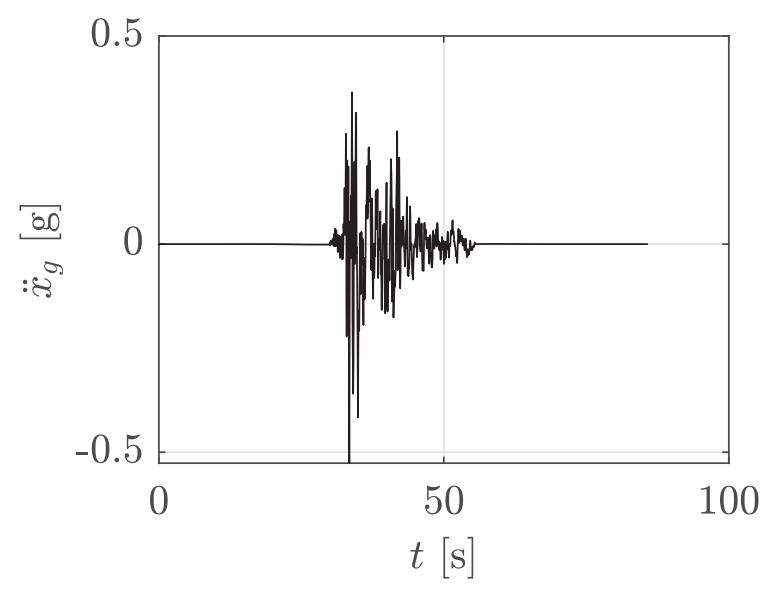

(a)

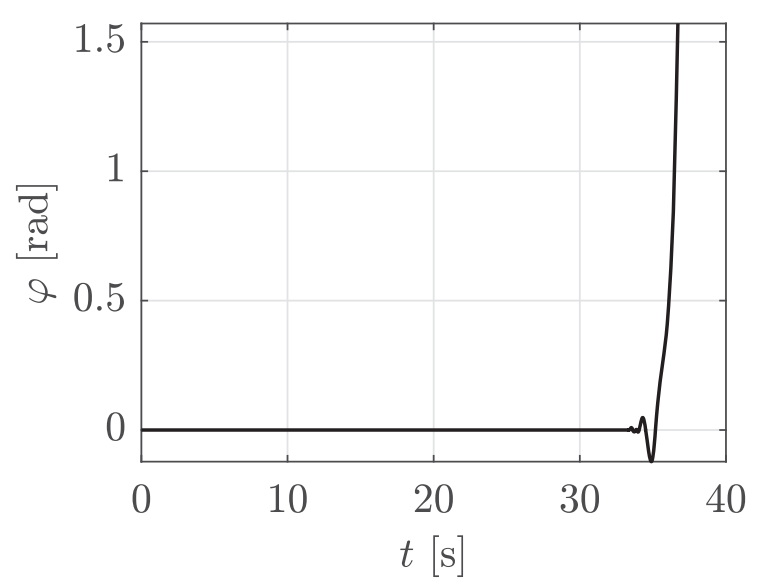

(b)

Figure 4: The East-West component of the Düzce earthquake acceleration recorded on the $12^{\text {th }}$ of November 1999 (a); Non-isolated Caryatid's rocking response (b).

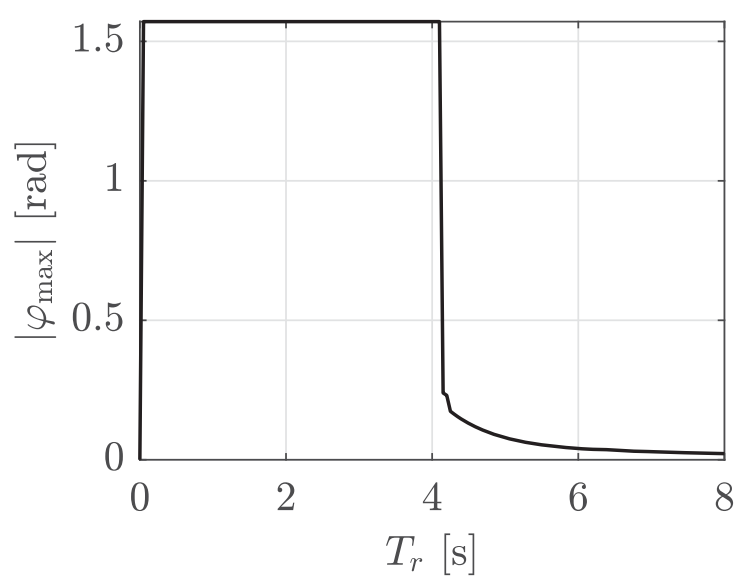

(a) Caryatid's Rocking spectrum

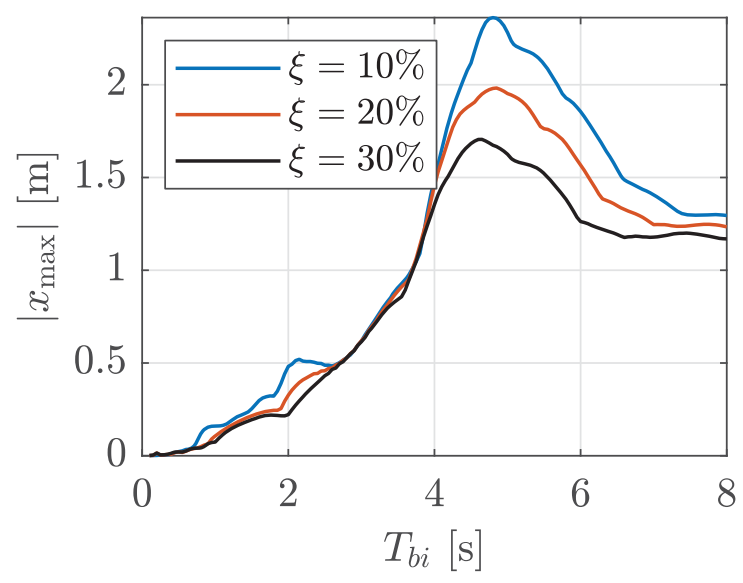

(b) Horizontal displacement spectrum for the isolated Caryatid with LRBs devices

Figure 5: Response spectra obtained from the Düzce earthquake acceleration.

The results are very satisfactory, given that the base-isolated Caryatid does not rock, removing the possibility of damage due to collisions. Moreover, the attained displacements are much smaller than the device's maximum assumed displacement whose value is shown in Tab. 1(a).

Table 1: LRBs' properties (a); The model constitutive parameters of the model (b).

\begin{tabular}{cccc}
\hline$n_{d}[-]$ & $T_{b i}[\mathrm{~s}]$ & $x_{\max }[\mathrm{m}]$ & $\xi[\%]$ \\
\hline 4 & 2 & 0.30 & 30 \\
\hline
\end{tabular}

(a)

\begin{tabular}{ccc}
\hline$k_{a}\left[\mathrm{~N} \mathrm{~m}^{-1}\right]$ & $k_{b}\left[\mathrm{~N} \mathrm{~m}^{-1}\right]$ & $\alpha[-]$ \\
\hline $6.22 \times 10^{4}$ & $6.22 \times 10^{3}$ & 44.69 \\
\hline
\end{tabular}

(b) 


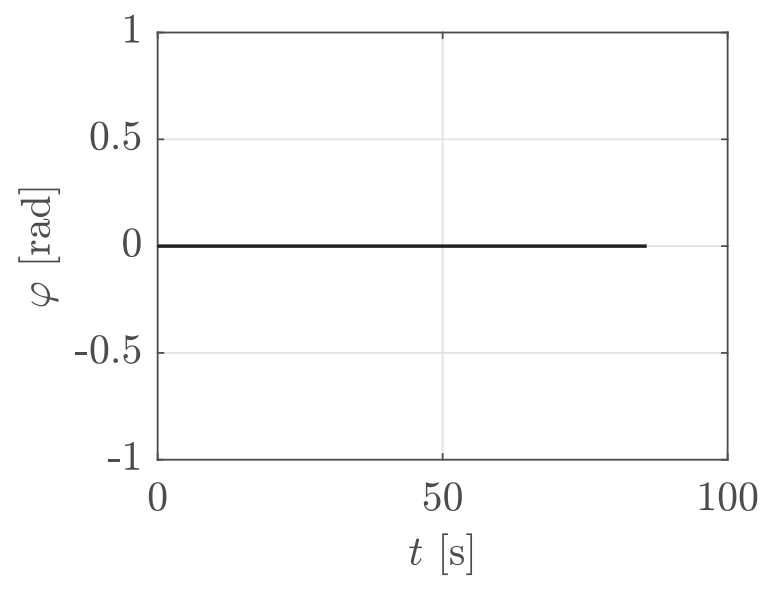

(a)

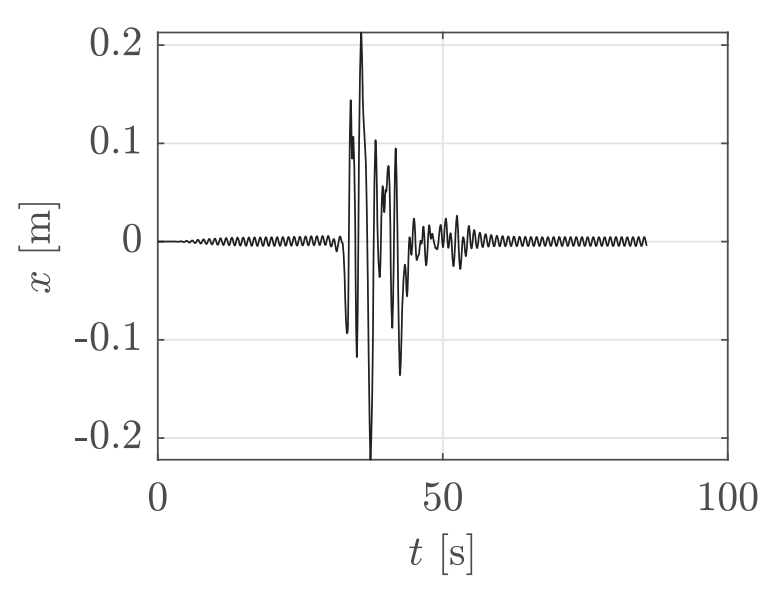

(b)

Figure 6: The rocking (a) and horizontal displacement (b) responses of the seismically baseisolated Caryatid.

\section{CONCLUSIONS}

The rocking behaviour of a Caryatid from the Erechtheion subjected to the 1999 Düzce earthquake (Turkey) has been investigated. After approximately thirty-five seconds the statue overturns. Consequently, a base isolation supported on four Lead Rubber Bearings as seismic protection system has been considered. We modelled the Caryatid object under study as a symmetric rigid body able to rock about one of the two bottom corners and assuming that sliding was prevented. Regarding the collisions, we applied the laws of conservation of linear and angular momentum in order to evaluate the angular and linear coefficients of restitution.

The complex hysteretic behaviour of the assumed elastomeric devices has been predicted by an innovative uniaxial phenomenological model of algebraic nature. As a consequence, the computational effort is drastically reduced, since there is no need to solve any differential equation to evaluate the device's restoring force as in the well-known Bouc-Wen model. In addition, the algebraic nature makes the model suitable for a design procedure able to provide the required constitutive parameters. The related procedure will be illustrated in a forthcoming paper [21].

Numerical assessments have been carried out on the Caryatid statue, with and without isolation. Firstly, we computed the rocking and horizontal displacement response spectra of the statue subjected to seismic excitation, in order to establish the isolation period and the device's maximum displacement to utilise. The results have shown that the Lead Rubber Bearings isolation system not only avoids overturning of the Caryatid, but it completely removes the rocking motion; hence, any kind of damage due to collision is avoided. Moreover, the horizontal displacements attained by the base-isolated are less than the maximum displacement allowed for the adopted device.

In future papers, further types of rate-independent hysteretic devices [24, 25, 26, 27, 28] will be employed to evaluate their capability in protecting rigid bodies from earthquake excitations.

\section{REFERENCES}

[1] F. Vestroni, S. Di Cinto, Base isolation for seismic protection of statues. Proceedings of 12th World Conference of Earthquake Engineering (WCEE 2000), Auckland, New 
Zealand, 30 January - 4 February, 2000.

[2] P. C. Roussis, E. A. Pavlou, E. C. Pisiara, Base-isolation technology for earthquake protection of art objects. Proceedings of 14th World Conference on Earthquake Engineering (WCEE 2008), Beijing, China, October 12-17, 2008.

[3] M. F. Vassiliou, N. Makris, Analysis of the rocking response of rigid blocks standing free on a seismically isolated base. Earthquake Engineering \& Structural Dynamics, 41(2), 177-196, 2012.

[4] S. Sorace, G. Terenzi, Seismic performance assessment and base-isolated floor protection of statues exhibited in museum halls. Bulletin of Earthquake Engineering, 13(6), 1873$1892,2015$.

[5] S. Baggio, L. Berto, T. Favaretto, A. Saetta, R. Vitaliani, Seismic isolation technique of marble sculptures at the Accademia Gallery in Florence: numerical calibration and simulation modelling. Bulletin of Earthquake Engineering, 13(9), 2719-2744, 2015.

[6] A. Gesualdo, A. Iannuzzo, M. Monaco, F. Penta, Rocking of a rigid block freestanding on a flat pedestal. Journal of Zhejiang University-SCIENCE A, 19(5), 331-345, 2018.

[7] I. E. Kavvadias, L. Vasiliadis, A. Elenas, K. Koutsoupakis, Fragility assessment of base isolated free standing museum artifacts. Proceedings of 6th Conference on Computational Methods in Structural Dynamics and Earthquake Engineering (COMPDYN 2019), Crete, Greece, 24-26 June, 2019.

[8] D. Pellecchia, S. Sessa, N. Vaiana, L. Rosati, Comparative Assessment on the Rocking Response of Seismically Base-Isolated Rigid Blocks. Procedia Structural Integrity, 29, 95-102, 2020.

[9] D. D'Angela, G. Magliulo, E. Cosenza, Towards a reliable seismic assessment of rocking components. Engineering Structures, 230, 111673, 2021.

[10] G. Zuccaro, F. Dato, F. Cacace, D. de Gregorio, S. Sessa, Seismic collapse mechanisms analyses and masonry structures typologies: A possible correlation. Ingegneria Sismica, 34(4), 121-149, 2017.

[11] G. De Canio, Marble devices for the Base isolation of the two Bronzes of Riace: a proposal for the David of Michelangelo. Proceedings of 15th World Conference on Earthquake Engineering (WCEE 2012), Lisbon, Portugal, September 24-28, 2012.

[12] I. Caliò, M. Marletta, On the mitigation of the seismic risk of art objects: case-studies. Proceedings of 13th World Conference on Earthquake Engineering (WCEE 2004), Vancouver, British Columbia, Canada, August 1-6, 2004.

[13] N. Vaiana, S. Sessa, F. Marmo, L. Rosati, A class of uniaxial phenomenological models for simulating hysteretic phenomena in rate-independent mechanical systems and materials. Nonlinear Dynamics, 93(3), 1647-1669, 2018.

[14] N. Vaiana, S. Sessa, L. Rosati, A generalized class of uniaxial rate-independent models for simulating asymmetric mechanical hysteresis phenomena. Mechanical Systems and Signal Processing, 146, 106984, 2021. 
[15] N. Vaiana, D. Losanno, N. Ravichandran, A novel family of multiple springs models suitable for biaxial rate-independent hysteretic behavior. Computers and Structures, 244, 106403, 2021.

[16] M. Constantinides, N. Makris, S. G. Miller. Seismic Response Analysis of Plaster Cast Sculptures on the University of California, Berkeley Campus, Report No. EERC 2003-07. Earthquake Engineering Research Center, 2003.

[17] N. Vaiana, S. Sessa, F. Marmo, L. Rosati, Nonlinear dynamic analysis of hysteretic mechanical systems by combining a novel rateindependent model and an explicit time integration method. Nonlinear Dynamics, 98(4), 2879-2901, 2019.

[18] R. Bouc, Modele mathematique d'hysteresis. Acustica, 24(1), 16--25, 1971.

[19] Y. K. Wen, Method for random vibration of hysteretic systems. Journal of the Engineering Mechanics Division, 102(2), 249--263, 1976.

[20] S. Sessa, N. Vaiana, M. Paradiso, L. Rosati, An inverse identification strategy for the mechanical parameters of a phenomenological hysteretic constitutive model. Mechanical Systems and Signal Processing, 139, 106622, 2020.

[21] D. Pellecchia, Elastomeric bearings-based isolation for seismic protection of art objects. To be submitted, 2021.

[22] N. Vaiana, S. Sessa, F. Marmo, L. Rosati, An accurate and computationally efficient uniaxial phenomenological model for steel and fiber reinforced elastomeric bearings. Composite Structures, 211, 196-212, 2019.

[23] L. Luzi, G. Lanzano, C. Felicetta, M. C. D’Amico, E. Russo, S. Sgobba, F. Pacor, \& ORFEUS Working Group 5. Engineering Strong Motion Database (ESM) (Version 2.0). Istituto Nazionale di Geofisica e Vulcanologia (INGV), 2020.

[24] D. Losanno, M. Spizzuoco, G. Serino, Optimal design of seismic isolation systems for simply supported bridges. Earthquakes and Structures, 7(6), 969-999, 2014.

[25] D. Losanno, H. A. Hadad, G. Serino, Seismic behavior of isolated bridges with additional damping under far-field and near fault ground motion. Earthquakes and Structures, 13(2), 119-130, 2017.

[26] D. Losanno, H. A. Hadad, G. Serino, Design charts for Eurocode based design procedure of elastomeric seismic isolation systems. Soil Dynamics and Earthquake Engineering, 119, 488-498, 2018.

[27] D. Losanno, M. Spizzuoco, A. Calabrese, Bidirectional shaking table tests of unbonded recycled rubber fiber reinforced bearings (RR-FRBs). Structural Control and Health Monitoring, e2386, 2019.

[28] D. Losanno, I. E. Madera Sierra, M. Spizzuoco, J. Marulanda, P. Thomson, Experimental Performance of Unbonded Polyester and Carbon Fiber Reinforced Elastomeric Isolators under Bidirectional Seismic Excitation. Engineering Structures, 209, 110003, 2020. 